\title{
A REFORMA UNIVERSITÁRIA DE 1968 E A ABERTURA PARA O ENSINO SUPERIOR PRIVADO NO BRASIL
}

\author{
Carlos Benedito Martins
}

\begin{abstract}
RESUMO: Este artigo tem como objetivo analisar o surgimento de um novo padrão de ensino superior que se instalou no Brasil a partir do final da década de 1950. O argumento defendido é que ele representou uma conseqüência da implantação da Reforma de 1968. Em função do modelo implantado, que procurou privilegiar uma estrutura seletiva, acadêmica e socialmente, o atendimento da crescente demanda por acesso ao ensino superior passou a ser feito pelo ensino privado, que se organizou por meio de empresas educacionais. $\mathrm{O}$ texto procura salientar as condições que tornaram possível a emergência dessas empresas. Conclui que a escalada da privatização não representou uma democratização do acesso ao ensino superior no país e da necessidade da retomada da expansão das universidades públicas, de modo especial das instituiçôes federais.
\end{abstract}

Palavras-chave: Ensino superior. Reforma universitária. Educação brasileira. Ensino público. Ensino privado empresarial.

THE 1968 REFORM AND THE OPENING OF DOORS TO PRIVATE HIGHER EDUCATION IN BRAZIL

ABSTRACT: This paper analyzes a new standard of higher education established in Brazil from the late 1950s on. Its argument is that this was a consequence of the 1968 Reform. Because of the model introduced, which privileged a selective structure, both socially and academically, the growing demand for access to higher education was met by the private sector whose institutions

Doutor em Sociologia e professor associado da Universidade de Brasília (UnB).

E-mail:carlosb@unb.br

Educ. Soc., Campinas, vol. 30, n. 106, p. 15-35, jan./abr. 2009

Disponível em <http://www.cedes.unicamp.br> 
organized themselves as educational enterprises. The text highlights the conditions that allowed this lucrative business to emerge. It concludes that this move towards privatization did not represent a democratization of the access to higher education in the country and points to the need to resume the expansion process of public universities, especially that of federal institutions.

Key words: Higher education. University reform. Brazilian education. Public education. Private education businesses.

\section{Introdução}

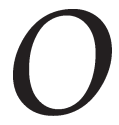

objetivo central deste artigo é esboçar a gênese do "novo" ensino superior privado que surgiu na sociedade brasileira na esteira da Reforma Universitária de 1968 e destacar sua inserção no interior do campo das instituições que o integram em sua fase atual. Parte-se do pressuposto de que a Reforma de 1968 visou fundamentalmente a modernização e expansão das instituições publicas, destacadamente das universidades federais. O surgimento do "novo" ensino superior privado constitui um desdobramento da Reforma de 1968, uma vez que as modificações introduzidas nas universidades federais não conseguiram ampliar satisfatoriamente suas matriculas para atender à crescente demanda de acesso (Bourdieu, 1997, 1994, 1992, 1980, 1976; Charle, 1983; Martins, 2002).

A Reforma de 1968 produziu efeitos paradoxais no ensino superior brasileiro. Por um lado, modernizou uma parte significativa das universidades federais e determinadas instituições estaduais e confessionais, que incorporaram gradualmente as modificações acadêmicas propostas pela Reforma. Criaram-se condiçôes propícias para que determinadas instituições passassem a articular as atividades de ensino e de pesquisa, que ate então - salvo raras exceções - estavam relativamente desconectadas. Aboliram-se as cátedras vitalícias, introduziu-se o regime departamental, institucionalizou-se a carreira acadêmica, a legislação pertinente acoplou o ingresso e a progressão docente à titulação acadêmica. Para atender a esse dispositivo, criou-se uma política nacional de pós-graduação, expressa nos planos nacionais de pós-graduação e conduzida de forma eficiente pelas agências de fomento do governo federal. Nos últimos 35 anos, a pós-graduação tornou-se um instrumento fundamental da renovação do ensino superior no país. 
Sua implantação impulsionou posteriormente um vigoroso programa de iniciação científica, que tem contribuído para articular pesquisa e ensino de graduação e impulsionado a formação de novas gerações de pesquisadores (Velloso, 2000; Martins, 2003, 2002; Barros, 1998).

Se a Reforma de 1968 produziu efeitos inovadores, por outro lado, abriu condições para o surgimento de um ensino privado que reproduziu o que Florestan Fernandes denominou o antigo padrão brasileiro de escola superior, ou seja, instituiçôes organizadas a partir de estabelecimentos isolados, voltados para a mera transmissão de conhecimentos de cunho marcadamente profissionalizante e distanciados da atividade de pesquisa, que pouco contribuem com a formação de um horizonte intelectual crítico para a análise da sociedade brasileira e das transformações de nossa época (Fernandes, 1975, p. 51-55).

O ensino superior privado que surgiu após a Reforma de 1968 tende a ser qualitativamente distinto, em termos de natureza e objetivos, do que existia no período precedente. Trata-se de outro sistema, estruturado nos moldes de empresas educacionais voltadas para a obtenção de lucro econômico e para o rápido atendimento de demandas do mercado educacional. Esse novo padrão, enquanto tendência, subverteu a concepção de ensino superior ancorada na busca da articulação entre ensino e pesquisa, na preservação da autonomia acadêmica do docente, no compromisso com o interesse público, convertendo sua clientela em consumidores educacionais (Altbach, 2005; Marginson, 2007).

Condições de surgimento do novo ensino privado

O ensino superior privado anterior à Reforma de 1968 se organizou de maneira bastante próxima ao ensino público. Não seria totalmente incorreto supor que o ensino privado então existente possuía um caráter semi-estatal. A esse propósito, deve-se assinalar que, durante um longo período, as universidades católicas permaneceram dependentes do financiamento do setor público para a sustentação de suas atividades (Casali, 1995; Antoniazzi, 1975).

O período de 1945-1965 se destacou por um crescimento acelerado do ensino superior público, sendo que, durante esse intervalo 
de tempo, suas matrículas saltaram de 21 mil para 182 mil estudantes. Nesse momento, ocorreu o processo de federalização de instituições estaduais e privadas, que foram integradas às nascentes universidades federais, por meio de entendimentos com os mantenedores de instituições privadas, de modo que a absorção de suas faculdades resultasse benéfica para eles. No período em foco, a participação do setor privado manteve-se estável, absorvendo $44 \%$ do total das matrículas (Vasconcelos, 2007; Cunha, 2004).

Os primeiros anos da década de 1960 foram marcados por um intenso movimento visando à reforma do sistema universitário brasileiro, do qual participaram os docentes, os pesquisadores e o movimento estudantil. A inserção dos docentes nessa mobilização traduzia as aspirações de cientistas e de jovens pesquisadores que haviam recebido uma formação no exterior e desejavam fazer da universidade um locus de produção de conhecimento científico. A Sociedade Brasileira para o Progresso da Ciência (SBPC) constituiu um fórum importante de suas reivindicações. Por sua vez, o movimento estudantil realizou seminários sobre a reforma universitária, nos quais criticava seu caráter elitista, denunciando igualmente a existência do regime de cátedra vitalícia, indicava a necessidade de realização de concursos públicos para a admissão de professores e lutava por currículos atualizados e pela ampliação da participação estudantil nos órgãos colegiados (Fernandes, 2000; Poerner, 1968; Veiga, 1982; Cunha, 1983; Sanfelice, 1986).

O "novo" ensino superior privado emergiu de uma constelação de fatores complexos, entre os quais se destacam, num primeiro momento, as modificações ocorridas no campo político nacional em 1964 e seu impacto na formulação da política educacional. Com a instauração do regime militar, as medidas repressivas desencadeadas pelos novos governantes, com relação ao movimento estudantil, e a estrita vigilância dos docentes se combinaram com propostas de modernização e de expansão do ensino superior.

Com relação ao dispositivo repressivo, vale mencionar o Decreto n. 4.464/64, que extinguiu a Uniāo Nacional dos Estudantes (UNE); o Decreto n. 228/67, que limitou a existência de organizações estudantis ao âmbito estrito de cada universidade; o Decreto n. 477/69, que impôs severas punições aos estudantes, professores ou funcionários que desenvolvessem atividades consideradas hostis ao regime militar, com a 
criação, no interior do MEC, de uma divisão de segurança e informação para fiscalizar as atividades políticas de professores e estudantes nas instituições. Houve, igualmente, aposentadorias compulsórias de professores considerados nocivos ao regime militar em várias universidades públicas (Fávero, 1995; Sanfelice, 1986; Fernandes, 1984).

Após o golpe de 1964, permanecia entre estudantes e professores um clima de insatisfação com a estrutura universitária existente. Em várias instituições, alunos e professores realizaram "cursos paralelos", expressando sua discordância com relação aos currículos existentes. Paralelamente, os estudantes se mobilizaram diante da incapacidade do ensino público de absorver os alunos aprovados nos vestibulares. Em 1960, 29 mil estudantes não conseguiram vagas nas instituições para as quais tinham sido aprovados, número que aumentou para $162 \mathrm{mil}$ em 1969. A questão dos "excedentes" constituiu-se num constante foco de tensão social. A pressão para a expansão do ensino superior estava relacionada à ampliação da taxa de matrícula do ensino médio, que cresceu 4,3 pontos entre 1947 e 1964 . Ao mesmo tempo, o processo de concentração da propriedade e de renda, em curso na sociedade brasileira desde a década de 1950, acentuado pela política econômica adotada a partir de 1964, conduziu as classes médias a encarar a educação superior como uma estratégia para a concretização de seu projeto de ascensão social (Cunha, 1975; Trigueiro, 1967).

Diante desse quadro, o governo militar se sentiu pressionado a formular uma política para a reestruturação do ensino superior. Ao contrário do que ocorrera no período populista, durante o qual vigorou uma discussão pública visando à construção de uma universidade crítica de si mesma e da sociedade brasileira, a política educacional do regime autoritário seria confiada a um pequeno grupo designado pelo poder central. O governo encomendou determinados estudos com o objetivo de propor medidas para o ensino superior, entre os quais se destacam o documento elaborado pelo professor norte-americano Rudolph Atcon; o Relatório Meira Mattos, que o abordou como uma questão de "segurança nacional", e o Relatório da Equipe de Assessoria do Ensino Superior, cuja comissão foi integrada por professores norte-americanos e brasileiros (Atcon, 1966; Relatório Meira Mattos, 1968; Relatório da Equipe de Assessoria ao Planejamento do Ensino Superior, 1969). 
Os diagnósticos e as recomendaçôes veiculados por esses documentos apresentam um alto grau de convergência. A educação superior deveria ter objetivos práticos e adaptar seus conteúdos às metas do desenvolvimento nacional. O sistema de ensino superior não poderia continuar atendendo a um público restrito, tal como vinha acontecendo. Propunha-se assim sua expansão, assinalando, no entanto, a falta de recursos financeiros, o que levou à introdução do princípio $d a$ expansão com contenção, que seria reiterado pela política educacional. O objetivo a ser alcançado era obter o máximo de atendimento da demanda com o menor custo financeiro. A reformulação do ensino superior deveria pautar-se por uma racionalização dos recursos e orientar-se pelo princípio de flexibilidade estrutural, evitando a duplicação de meios para as mesmas finalidades acadêmicas.

A partir dessa perspectiva, recomendava-se a eliminação da cátedra vitalícia, a criação dos departamentos, a introdução do ciclo básico no primeiro ano de formação universitária como um mecanismo para contornar as pressões dos "excedentes". Sugeria-se também modificaçóes no exame vestibular, que deveria tornar-se "classificatório", visando à incorporação de um maior número de estudantes. O documento elaborado pela Equipe de Assessoria do Ensino Superior faz uma clara menção à participação do ensino privado no processo de expansão. Nessa direção, assinalava que o governo deveria estimular a criação de universidades particulares, prestando-lhes auxílio, a fim de assegurar vagas para alunos com poucos recursos financeiros (Relatório da Equipe de Assessoria do Ensino Superior, 1969, p 56).

A revolta estudantil que ocorreu em vários países, em 1968, assumiu diferentes matizes políticos segundo o contexto sócio-histórico no qual se inseria. No Brasil, além da luta pela restauração da democracia, os estudantes continuavam pressionando o regime militar no sentido da reestruturação e da expansão do ensino superior. Nesse contexto, o governo instituiu, em 1969, o Grupo de Trabalho da Reforma Universitária para propor "soluçôes realistas" e "medidas operacionais", com o objetivo de conferir eficiência e produtividade ao sistema. O GT da Reforma Universitária incorporaria várias recomendaçôes dos trabalhos mencionados anteriormente, ressaltando o papel estratégico do ensino superior no processo de desenvolvimento econômico. Repetiuse no GT o princípio da expansão com contenção e a recomendação de 
plena utilização dos recursos materiais e humanos das instituiçôes universitárias, o que o levou a propor as mesmas medidas acima mencionadas, ou seja, a criação dos departamentos, a institucionalização da carreira acadêmica, a introdução do ciclo básico, o regime de créditos. Uma de suas principais recomendaçôes, apoiada no Parecer n. 977/65 elaborado por Newton Sucupira, refere-se à implantação dos cursos de pós-graduação (Lipset, 1971; Wallerstein, 1971; Touraine, 1968; Relatório do GT da Reforma Universitária, 1969; Parecer n. 977/65).

Embora não fizesse menção à participação do ensino privado no processo de expansão, o GT abriu brechas para sua posterior presença no campo do ensino superior. Ao permitir a existência dos estabelecimentos isolados em "caráter excepcional" - uma vez que a universidade deveria constituir o "tipo natural de estrutura para o ensino superior" -, o GT criou condiçōes favoráveis ao processo de privatização que viria logo em seguida, ancorado na criação de estabelecimentos isolados. A produção de um discurso oficial que insistia na escassez de recursos financeiros permitiria, num momento posterior, evocar a situação de "complementaridade" da rede privada na ampliação do sistema. Deve-se destacar que a Constituição de 1967 disponibilizou recursos financeiros e ajuda técnica ao ensino particular (Sousa, 2006; Horta, 1996).

$\mathrm{O}$ argumento da escassez de recursos não impediu que o governo militar criasse um eficiente sistema de fomento para a sua política de desenvolvimento científico-tecnológico, visando a formação de recursos humanos altamente qualificados. Num primeiro momento, o BNDE e, posteriormente, a FINEP passaram a fornecer auxílios financeiros às instituiçôes publicas, por meio do Fundo de Desenvolvimento Técnico-Científico, criado em 1964, que muito contribuiu com a instalação inicial da pós-graduação. As universidades federais receberam recursos financeiros que lhes possibilitaram a edificação de novos campi universitários, a construção de laboratórios, a institucionalização da carreira docente etc. Estruturava-se, nesse momento, um modelo duplamente seletivo de universidade federal: no plano social, suas vagas passariam a ser ocupadas por um grupo restrito de estudantes dotados de razoável volume de capital econômico e/ou cultural; no plano acadêmico, procurava-se concretizar um elevado padrão de qualidade acadêmica, fundado na associação entre ensino e pesquisa, no interior do 
qual a pós-graduação exerceria um papel central. A motivação subjacente a esse modelo era preservar as universidades federais de um eventual processo de massificação (Cunha, 2004; Ferrari, 2001; Barros, 1998).

A implantação desse modelo contribuiu para limitar a expansão das universidades públicas, em particular das federais. Seria incorreto afirmar que o ensino público não cresceu, uma vez que, no período de 1967 a 1980, suas matrículas passaram de 88 mil para aproximadamente 500 mil estudantes, registrando um crescimento da ordem de $453 \%$. Esse aumento ficou aquém das necessidades de acesso ao ensino superior, abrindo um flanco favorável à participação do ensino privado. Vale destacar que o ensino universitário católico mostrou-se reticente em expandir sua rede para absorver essa demanda, mantendo uma concepção de universidade voltada para o atendimento da reprodução das elites locais (Salem, 1982).

Entre as condições que tornaram possível a emergência do novo ensino privado, a existência do Conselho Federal de Educação (CFE) desempenhou um papel relevante. $\mathrm{O}$ CFE foi fortalecido pela aprovação da LDB, em 1961, quando deixou de ser um órgão de assessoramento sobre questôes educacionais e passou a deliberar sobre abertura e funcionamento de instituiçôes de ensino superior. Era composto majoritariamente por personalidades ligadas ao ensino privado, com disposição favorável para acolher os pedidos de abertura de novas instituições particulares. Entre 1968 e 1972, foram encaminhados ao CFE 938 pedidos de abertura de novos cursos, dos quais 759 obtiveram respostas positivas. A grande maioria dessas solicitações emanava da iniciativa privada não-confessional, que vinha atuando nos ensino primário e secundário e fora comprimida, no final dos anos de 1960, em função do crescimento da rede pública. Percebendo a existência de uma demanda não atendida pelo ensino público, os proprietários de escolas e colégios passaram a deslocar parte de seus investimentos para a abertura de novas instituições, sob o olhar conivente do CFE (Horta, 1975).

O forte controle político que pesava sobre o meio acadêmico cerceou o movimento de contestação à proliferação dos estabelecimentos particulares e inviabilizou a defesa do ensino público, que mobilizara parte significativa dos educadores na década de 1950. A adesão dos proprietários desses novos estabelecimentos aos valores do regime 
autoritário, assim como as alianças políticas subterrâneas que estabeleceram com os detentores do poder, criou condições vantajosas para a ampliação de seus negócios. Além de introduzir uma mentalidade empresarial no ensino superior, importaram também o controle de comportamento, com o qual estavam habituados a tratar os professores de seus colégios, e estabeleceram estreita vigilância ideológica no interior de suas instituições, impedindo a emergência da produção de um conhecimento crítico em seus estabelecimentos (Tragtemberg, 1982; Martins, 1988).

$\mathrm{Na}$ medida em que o ensino superior privado empresarial se expandiu, descolou-se das bases de apoio político do regime militar e foi adquirindo uma vida própria, em termos de atuação no interior do sistema. Para tanto, construiu poderosas associações, tal como a Associação Brasileira das Mantenedoras de Ensino Superior (ABMES), que passaram a desenvolver um intenso trabalho de construção de identidade institucional desse segmento e organizar a defesa de seus interesses junto ao poder público e perante a sociedade civil (ABMES, 2002).

\section{A escalada da privatização}

Entre 1965 e 1980, as matrículas do setor privado saltaram de 142 mil para 885 mil alunos, passando de $44 \%$ do total das matrículas para $64 \%$ nesse período. Em sua fase inicial, ou seja, desde o final dos anos de 1960 até a década de 1970, a expansão do setor privado laico ocorreu basicamente através da proliferação de estabelecimentos isolados de pequeno porte. A partir da segunda metade da década de 1970, o processo de organização institucional do setor privado sofreu uma transformação gradual. Num primeiro momento, alguns estabelecimentos isolados transformaram-se em federações de escolas, através de um processo de fusão. Num momento posterior, a partir do final da década de 1980, o movimento de transformação de estabelecimentos isolados em universidades se acelerou: entre 1985 e 1996, o número de universidades particulares mais do que triplicou, passando de 20 a 64 estabelecimentos. Tudo leva a crer que a expansão das universidades privadas foi orientada pela percepção de seus proprietários de que a existência de estabelecimentos maiores, oferecendo cursos mais diversificados, teria vantagens competitivas no interior do mercado do ensino superior. 
Por outro lado, o movimento de criação de novas universidades particulares foi impulsionado pela nova legislação do ensino superior. Ao dispor sobre o princípio da autonomia para as universidades, a Constituição de 1988 possibilitou ao setor privado criar e extinguir cursos na própria sede das instituições e remanejar o número de vagas dos cursos oferecidos, sem se submeter ao controle burocrático de órgãos oficiais. A criação dessas novas universidades particulares visava também obter um maior rendimento simbólico no interior do campo do ensino superior, pois formalmente elas passavam a se distinguir academicamente das faculdades isoladas e outros tipos de instituições. Em boa medida, várias dessas universidades com fins lucrativos, criadas nas últimas décadas, constituem um simulacro de verdadeiras universidades, pois tendem a funcionar como um conglomerado de escolas profissionais que não consolidaram a carreira acadêmica de seus professores e não institucionalizaram a pesquisa em seu interior (Barreyro, 2008; Altbach, 2005; Sampaio, 2000).

$\mathrm{Na}$ década de 1980, em função da crise econômica vivenciada pelo país, expressa num grave quadro inflacionário e no aumento das taxas de desemprego, ocorreu uma desaceleração da expansão do ensino superior. Surgiram, ao mesmo tempo, críticas sobre a qualidade do ensino privado por parte de várias associações profissionais e de outros segmentos da sociedade civil. Diante desse descontentamento, o governo, por meio de seus órgãos competentes, adotou medidas legais com o propósito de suspender temporariamente a criação de novos cursos nos estabelecimentos existentes. Nesse mesmo período, as instituições públicas passaram a se instalar em áreas geográficas de menor interesse econômico para a rede privada. Com efeito, entre 1980 e 1985, ocorreu uma pequena diminuição das matrículas do setor privado, de 885 mil para 811 no total. Inversamente, no mesmo período, as matrículas do ensino público cresceram de 492 mil a 556 mil estudantes (Sousa, 2006; Sobral, 2001).

No início da década de 1990, o ensino privado respondia por $62 \%$ do total das matrículas, ocorrendo uma pequena diminuição em 1995 , quando passou a absorver $60 \%$ dos alunos de graduação. A partir dessa data, coincidindo com os dois mandatos de FHC, intensificou-se a presença das instituiçôes particulares no interior do campo do ensino superior. A extinção do CFE, no final do governo Itamar Franco, e a criação do Conselho Nacional de Educação (CNE) conferiram ao MEC uma maior autonomia 
na condução do processo de expansão do ensino superior. $\mathrm{O}$ CNE adotou uma política de flexibilização diante dos processos de autorização, reconhecimento e credenciamento de cursos e de instituições particulares. Tudo leva a crer que a lógica subjacente a essa postura repousava na crença de que o próprio mercado acadêmico regularia o desempenho das instituições, mediante o sistema de avaliação do Exame Nacional de Cursos ("Provão"), introduzido em 1996, e pela Avaliação das Condições de Oferta, implantada em 1997 (Vieira \& Farias, 2007; Caixeta, 2002).

Supunha-se que, na condição de consumidores educacionais, os estudantes e suas famílias orientariam suas escolhas através dos resultados do sistema de avaliação, o que contribuiria indiretamente, numa lógica competitiva, para as instituições aumentarem a qualidade de seus produtos. Por sua vez, o total de recursos do Tesouro Nacional, incluindo os recursos para pessoal, nunca ultrapassou 0,90\% do PIB de 1995 a 2002. Os recursos para investimentos (incluindo recursos próprios) nas IFES variaram de cerca de R \$ 150 milhões para menos de R $\$ 50$ milhões nesse período. O Ministério da Educação incentivou as instituições federais a expandir a oferta de vagas a partir dos recursos humanos e físicos existentes, num contexto do aumento expressivo de aposentadorias de docentes e de funcionários. Ao mesmo tempo, houve suspensão de concursos públicos para o preenchimento de novas vagas, acarretando a precarização do trabalho docente e um expressivo recrutamento de professores substitutos (Corbucci, 2000 e 2004).

Nesse momento, os responsáveis pela política educacional no país incorporaram determinados princípios das agendas de organismos internacionais, que recomendavam a desregulamentação do ensino superior, a retração de gastos governamentais para esse nível de ensino e o incremento de investimentos na educação básica, o que incentivou ainda mais a expansão das instituições privadas, não só no Brasil, mas em vários países. Entre 1995 e 2002, as matrículas saltaram de 1,7 milhões para 3,5 milhões de estudantes, um crescimento da ordem de $209 \%$. Se o ensino público experimentou um aumento em termos de matrículas, foi o setor privado que comandou essa expansão, uma vez que suas matrículas de graduação cresceram de $60 \%$ para $70 \%$. O número de universidades públicas ficou praticamente estagnado, ao contrário das universidades privadas, que passaram de 63 para 84 estabelecimentos. Dos 77 centros universitários criados no contexto da reorganização acadêmica das instituiçôes de ensino, 74 eram privados (Marginson, 
2007; McCowan, 2007; Boron, 2006; Guadilla, 2005; Torres \& Rhoadds, 2006; Stromquist, 2002).

Estabeleceu-se também, nesse momento, uma legislação federal com o propósito de diferenciar as instituições comunitárias dos estabelecimentos privados com fins lucrativos, impedidos de receber recursos públicos e de gozar de imunidade fiscal (Decreto n. 2207/1997). Com isso, institucionalizou-se um capitalismo acadêmico, no qual os investimentos realizados pelas instituições de ensino deveriam seguir as mesmas normas que informam a regulação dos demais setores do campo econômico (Slaughter \& Rhoades, 2004; Corbucci, 2004).

De 1990 a 2002, a demanda por educação superior, expressa através do número de inscrições no vestibular, cresceu aproximadamente em $160 \%$ e a oferta de vagas aumentou para $252 \%$. Devido à retração das vagas na rede federal, a absorção dessa demanda foi realizada em larga medida pelas instituições privadas. A expansão da oferta contribuiu para a redução do número de candidatos por vagas, de 3,8 para 2,8 nesse período. No entanto, o ensino público continuou sendo o mais procurado, registrando inclusive um aumento de 5,7 candidatos em 1990 para 8,9 em 2004, ao passo que o ensino privado acusou, no mesmo período, uma redução de 2,9 para 1,6 candidatos. Não obstante o expressivo crescimento das matrículas nos cursos de graduação nas últimas décadas, existem indícios de que a política de expansão através da via privada começa a dar claros sinais de exaustão: em $2004,49 \%$ das vagas do setor privado estavam sem ocupação e houve também um aumento significativo do número de estudantes inadimplentes (Barreyro, 2008; Corbucci, 2004).

A mudança de governo, em 2003, acarretou a reorientação da política educacional, no sentido de fortalecer o ensino público, sobretudo nas universidades federais. Embora a gestão do primeiro ministro do novo governo não sinalizasse claramente a recuperação das instituições federais, a partir de 2004 foram colocadas em prática determinadas ações visando reverter a situação adversa em que estas se encontravam nos anos anteriores. Seu orçamento foi recuperado, houve implantação de novas unidades, contratação de novos docentes e funcionários mediante concurso público, cujos salários foram atualizados. Visando à democratização do acesso e à permanência dos alunos no ensino superior, o governo instituiu, em 2004, o Programa Universidade 
para Todos (PROUNI), que tem sido objeto de avaliações controversas no meio acadêmico (Carvalho, 2006).

Nesse mesmo ano, o governo apresentou um projeto de Reforma Universitária que, ao contrário da realizada em 1968, foi amplamente debatido pela comunidade acadêmica e pela sociedade civil. Entre outros aspectos, o projeto busca recuperar o papel do Estado como ator central na condução do sistema de ensino superior, estabelecendo um marco regulatório para o funcionamento dos estabelecimentos públicos e privados. Procura também recuperar a importância das instituiçóes federais, estipulando que a União aplicaria nelas, durante dez anos, um valor nunca inferior a $75 \%$ da receita constitucionalmente vinculada à manutenção e ao desenvolvimento do ensino, excluindo desse montante as despesas realizadas com os aposentados. Lamentavelmente, o projeto de Reforma Universitária encontra-se em estado de letargia no poder legislativo, por ser objeto de apreciações divergentes (Martins, 2006; Sguissardi, 2006).

Em abril de 2007, o governo federal instituiu o Programa de Apoio aos Planos de Reestruturação e Expansão das Universidades Federais (REUNI), que visa dotá-las dos recursos financeiros necessários à ampliação do acesso, aumentar a qualidade dos seus cursos, melhorar o aproveitamento das estruturas físicas e rever sua arquitetura acadêmica. O REUNI procura concretizar determinados marcos do Plano Nacional de Educação, que estabeleceu a meta de oferecer educação superior a pelo menos 30\% dos jovens na faixa etária de 18-24 anos até 2010 (Presidência da República, 2007).

A escala da privatização torna-se saliente quando se examina os dados mais recentes relativos ao ensino superior. Em 2006, estavam matriculados na graduação 4,7 milhões de alunos, dos quais $74 \%$ estudavam em estabelecimentos privados. O setor particular com fins lucrativos absorvia $41 \%$ das matrículas. As instituiçôes federais respondiam por $12 \%$, as estaduais por $10 \%$ e as municipais por 3\% do total das matrículas. Existiam 2.270 instituições de graduação de diferentes tamanhos e com diversas vocações acadêmicas, das quais $89 \%$ pertenciam ao setor privado. O setor com fins lucrativos representava $78 \%$ do total das instituições privadas.

No processo de escalada da privatização, algumas instituições particulares de perfil comercial romperam as fronteiras regionais, 
associaram-se comercialmente com estabelecimentos estrangeiros, colocaram ações na bolsa de valores e, mais recentemente, passaram a atuar em outros países (Currie \& Newson, 1998).

\section{Considerações finais}

O "novo" ensino superior privado de perfil empresarial surgiu na medida em que as universidades públicas, sobretudo as federais, modernizadas pela Reforma Universitária de 1968, não conseguiram atender à crescente demanda de acesso. Sua expansão foi possível devido à retração do ensino público na absorção da demanda. As complexas alianças políticas que os proprietários das empresas educacionais estabeleceram com determinados atores dos poderes executivo e legislativo, nas últimas quatro décadas, possibilitaram essa multiplicação. Por sua vez, o espesso cipoal de leis, decretos, resoluções de conselhos e portarias ministeriais que se instalou no país lhes permitiu descumprir determinações legais que regulamentam o funcionamento das instituições e/ou reverter decisóes desfavoráveis aos seus interesses junto ao poder judiciário.

Nesses últimos quarenta anos, o ensino superior brasileiro se estruturou como um campo acadêmico complexo, heterogêneo, no qual as instituições passaram a ocupar posições dominantes e/ou dominadas em função dos critérios específicos que definem o prestígio e o reconhecimento dos estabelecimentos. Não seria de todo incorreto levantar a suposição de que houve, nas últimas décadas, um processo de hierarquização acadêmica no interior do campo do ensino superior brasileiro.

Dessa forma, algumas universidades públicas (federais e estaduais) e determinadas universidades privadas (geralmente as confessionais) se organizaram gradualmente, de modo a se aproximarem de um modelo acadêmico neo-humboldtiano. Essas instituições criaram estruturas acadêmicas que propiciaram a produção científica institucionalizada, desenvolveram cursos de pós-graduação stricto sensu, promoveram a profissionalização da carreira acadêmica, adotaram o regime de tempo integral para seus docentes, preservaram a liberdade acadêmica, associaram as atividades de ensino e pesquisa, implantaram programas de iniciação cientifica em parceria com agências de fomento nacionais. Em 
2006, as universidades públicas federais e estaduais concentravam $70 \%$ dos docentes de tempo integral e 64\% dos doutores no país (Scott, 2006; Sguissardi, 2005; Casper \& Humbolt, 1997; Charle \& Verger, 1994).

Por sua vez, as instituições privadas de perfil empresarial estruturaram atividades que guardam certas afinidades acadêmicas com o modelo neo-napoleônico. De modo geral, essas instituiçôes basicamente estão voltadas para uma estrita formação profissional e empregam professores horistas com pequeno volume de titulação acadêmica, que se dedicam em sua maior parte às atividades de ensino. Predomina em seu interior uma ausência de estruturas consolidadas de pesquisa e de pós-graduação stricto sensu. As instituições particulares com fins lucrativos concentram apenas 14\% dos docentes de tempo integral e 16\% dos doutores do país.

Existem diferenças qualitativas entre as instituições públicas e privadas, mas é também possível constatar assimetrias no interior de cada um desses segmentos.

A forma pela qual se deu a expansão do ensino superior no período em foco torna evidente que a simples ampliação de vagas no setor privado não ofereceu nenhuma garantia para sua democratização. $\mathrm{O}$ acesso ao ensino superior brasileiro continua restrito a aproximadamente $12 \%$ dos estudantes na faixa etária de 18-24 anos, o que contrasta com países mais avançados que têm absorvido aproximadamente $60 \%$ de jovens dessa faixa de idade (Barreyro, 2008; McCowan, 2007; Neves, 2005).

A retomada do projeto de reforma universitária poderia oferecer uma oportunidade à construção de um novo pacto acadêmico entre os diferentes atores e segmentos institucionais envolvidos nesse campo. Uma questão central a ser enfrentada diz respeito à restauração do princípio que atribui à educação superior a qualidade de um bem público, um direito inalienável do cidadão. O funcionamento do ensino privado de perfil empresarial, regido pelo livre jogo do mercado, transformou um direito da cidadania moderna num privilégio individual, convertendo sua clientela em consumidores de produtos educacionais, impondo pesados custos financeiros e humanos a uma parte expressiva dos seus estudantes. Uma educação superior comprometida com o interesse público implica que o Estado, de forma democrática, torne ator 
central na regulação e supervisão do sistema. A democratização do acesso ao ensino superior passa necessariamente pela recuperação da centralidade das universidades públicas, onde as instituições federais devem ser revigoradas, dotadas de efetiva autonomia administrativo-financeira e decididamente apoiadas pelo poder central, de modo a resgatar sua capacidade de funcionamento e expansão. Torna-se também de fundamental importância reverter a lógica de funcionamento do ensino privado - movido pelo anseio frenético de acumulação de ganhos materiais -, de forma que assuma uma efetiva dimensão de bem público. Em função das sólidas alianças sociais e políticas que as empresas educacionais construíram no país e de sua ávida lógica mercantil, a questão que se coloca é: Será isso ainda possível?

Recebido em setembro de 2008 e aprovado em dezembro de 2008.

\section{Referências}

ALTBACH, P. Private higher education: a global revolution. Boston: Center for International Higher Education, 2005.

ANTONIAZZI, A. Tendências atuais das universidades católicas no Brasil. Vozes, Petrópolis, v. 69, n. 9, out. 1975.

ASSOCIAÇÃO BRASILEIRA DE MANTENEDORES DO ENSINO SUPERIOR (abmes). Políticas de educação superior: desafios e proposições. Brasília, DF: ABMES, 2002.

ATCON, R. Rumo à reformulação estrutural da universidade brasileira. Rio de Janeiro: MEC, 1966.

BARREYRO, G.B. Mapa do ensino superior privado. Brasília, DF: MEC/ INEP, 2008.

BARROS, E.C. A política de pós-graduação: um estudo da participação da comunidade científica. São Carlos: UFSCAR, 1998.

BORON, A. Reforming the reforms: transformation and crisis in Latin American and Caribbean universities. In: TORRES, C.A.; RHOADS, R. (Org.). The university, State and market: the political economy of globalization in the Americas. Stanford: Stanford University, 2006. 
BOURDIEU, P. Le champ scientifique. Actes de la Recherche en Sciences Sociales, Paris, n. 2/3, p. 88-104, jun. 1976.

BOURDIEU, P. Questions de sociologie. Paris: Minuit, 1980.

BOURDIEU, P. Choses dites. Paris: Minuit, 1987.

BOURDIEU, P. (com Loïc Wacquant). Réponses. Paris: Seuil, 1992.

BOURDIEU, P. Raisons pratiques: sur la théorie de l'action. Paris: Seuil, 1994.

BOURDIEU, P. Méditations pascaliennes. Paris: Seuil, 1997

BOURDIEU, P. et al. Les stratégies de reconversion. Information sur les Sciences Sociales, Paris, v. 12, n. 5, p. 61-113, out. 1973.

BRASIL. Ministério da Educação. Reestruturação e expansão das universidades federais (reuni): diretrizes gerais. Brasília, DF: MEC, 2007

CAIXETA, N. Educação. In: Lamounier, B.; Figueiredo, R. (Org.). A era FHC: um balanço. São Paulo: Cultura, 2002.

CARVALHO, C.A. O PROUni no governo Lula e o jogo político em torno do acesso ao ensino superior. Educação \& Sociedade, Campinas, v. 27, n. 96, p. 979-1000, 2006.

CASALI, A. Elite intelectual e a restauração da Igreja. Petrópolis: Vozes, 1995.

CASPER, G.; HUMBOLT,W. Um mundo sem universidades? Rio de Janeiro: UERJ, 1997.

CHARLE, C. Le champ universitaire parisien à la fin du $19^{\text {ème }}$ siècle. Actes de la Recherche en Sciences Sociales, Paris, n. 47/48, jun. 1983.

CHARLE, C.; VERGER, J. Histoire des universités. Paris: PUF, 1994.

CORBUCCI, P.R. As universidades federais: gastos, desempenho, eficiência e produtividade. Brasília: DF: IPEA, 2000.

CORBUCCI, P.R. Financiamento e democratização do acesso à educação superior no Brasil: da desserção do Estado ao projeto de reforma. Educação \& Sociedade, Campinas, v. 25, n. 88, p. 677-701, out. 2004. 
CUNHA, L.A. A expansão do ensino superior: causas e conseqüências. Debate \& Crítica, São Paulo, n. 5, p. 27-58, 1975.

CUNHA, L.A. A universidade crítica: o ensino superior na república populista. Rio de Janeiro: Francisco Alves, 1983.

CUNHA, L.A. Desenvolvimento desigual e combinado no ensino superior: Estado e mercado. Educação \& Sociedade, Campinas, v. 25, n. 88 , p. 795-817, out. 2004.

CURRIE, J.; NEWSON, J. Universities and globalization. London: Sage, 1998.

DURHAN, E. Educação superior, pública e privada. In: Brock, C.; Schwartzman, S. (Org.). Os desafios da educação no Brasil. Rio de Janeiro: Nova Fronteira, 2005. p. 197-240.

FÁVERO, M.L. A UNE em tempos de autoritarismo. Rio de Janeiro: UFRJ, 1995.

FERNANDES, A.M. A construção da ciência no Brasil e a SBPC. Brasília, DF: UnB, 2000.

FERNANDES, F. Universidade brasileira: reforma ou revolução? São Paulo: Alfa-Ômega, 1975.

FERNANDES, F. A questão da USP. São Paulo: Brasiliense, 1984.

FERRARI, A.F. José Pelúcio Ferreira e a pós-graduação no Brasil. Brasília, DF: Paralelo 15, 2001.

GUADILLA, G.C. Educación superior latinoamericana en los albores del tercer milenio. Caracas: Centro de Estudios del Desarollo, 2005.

HORTA, J.S. A expansão do ensino superior no Brasil. Vozes, Petrópolis, v. 69, n. 6, 1975.

HORTA, J.S. A educação no Congresso Constituinte 1966-1967. In: Fávero, O. (Org.). A educação nas Constituintes (1823-1988). Campinas: Autores Associados, 1996.

LEGISLAÇÃO e Normas da Pós-Graduação Brasileira: Parecer n. 977/65. Brasília, DF: FUNADESP, 2001. 
LIPSET, S.M. Rebellion in the university. Chicago: University of Chicago, 1971.

MARGISON, S. The public/private divide in higher education: a global revision. Higher Education, Amsterdam, v. 53, n. 3, p. 307-333, 2007.

MARTINS, C.B. Le nouvel enseigment supérieur privé au Brésil (19641983): rencontre d'une demande sociale et d'une opportunité politique. 1986. Tese (Doutorado) - Universidade de Paris V, Paris.

MARTINS, C.B. Ensino pago: um retrato sem retoques. São Paulo: Cortez, 1988.

MARTINS, C.B. A CAPES e a formação do sistema nacional de pósgraduação. In: CAPES 50 anos. Rio de Janeiro: FGV, 2002.

MARTINS, C.B. Sobre a noção da prática em Bourdieu. Novos Estudos CEBRAP, São Paulo, n. 62, p.163-181, mar. 2002.

MARTINS, C.B. A pós-graduação no contexto do ensino superior brasileiro. In: MoRHY, L. (Org.). Universidade em questão. Brasília, DF: UnB, 2003.

MARTINS, C.B. Uma reforma necessária. Educação \& Sociedade, Campinas, v. 27, n. 96, p. 1001-1020, out. 2006.

MCCOWAN, T. Expansion without equity: an analysis of current policy on access to higher education in Brazil. Higher Education, Amsterdam, v. 53, n. 5, p. 579-598, 2007.

NEVES, C.B. Educação Superior para todos? Acesso, expansão e eqüidade: novos desafios para a política educacional. Cadernos de Sociologia, Porto Alegre, v. 9, n. 17, p. 157. 2005.

POERNER, A. O poder jovem. Rio de Janeiro: Civilização Brasileira, 1968.

RELATÓRIO da Equipe de Assessoria ao Planejamento do Ensino Superior. Rio de Janeiro: Ministério da Educação e Cultura, 1969.

RELATÓRIO do Grupo de Trabalho da Reforma Universitária. Revista Brasileira de Estudos Pedagógicos, Brasília, DF, v. 50, n. 111, p. 119-175, jul./set. 1969. 
RELATÓRIO Meira Matos. Paz \& Terra, Rio de Janeiro, v. 4, n. 9, p. 199-241, out. 1969.

SALEM, T. Do Centro Dom Vital à Universidade Católica. In: SChWARTZMAn, S. (Org.). Universidades e instituiçôes católicas no Rio de Janeiro. Brasília, DF: CNPq, 1982.

SAMPAIO, H. O ensino superior no Brasil: o setor privado. São Paulo: Hucitec, 2000.

SANFELICE, J.L. Movimento estudantil: a UNE na resistência ao golpe de 1964. São Paulo: Cortez, 1986.

SCOTT, J. The mission of the university: medieval to posmoderm transformations. Journal of Higher Education, Ohio, v. 77, n. 1, 2006.

SGUISSARDI, V. Universidade pública estatal: entre o público e o privado-mercantil. Educação \& Sociedade, Campinas, v. 26, n. 90, p. 191-222, out. 2005.

SGUISSARDI, V. Reforma universitária no Brasil (1995-2006): precária trajetória e incerto futuro. Educação \& Sociedade, Campinas, v. 28, n. 96, p. 1021-1056, 2006.

SLAUGHTER, S.; RHOADES, R. Academic capitalism and the new economy. Baltimore: John Hopkins, 2004.

SOBRAL, F.A. A educação para a competitividade ou para a cidadania? São Paulo em Perspectiva, São Paulo, v. 14, n. 1, jan. 2001.

SOUSA, J.V. Restrição do público e estímulo à iniciativa privada: tendência histórica no ensino superior brasileiro. In: Silva, M.A.; Silva, R.B. (Org.). A idéia de universidade. Brasília, DF: Líber Livro, 2006.

STROMQUIST, N. Education in a globalized world. New York: Rowman \& Littlefield, 2002.

TORRES, C.A.; RHOADS, R. Introduction. In: TORRES, C.A.; RHOADS, R. (Org.). Globalization and higher education in the Americas. Stanford: Stanford University, 2006.

TOURAINE, A. Le communisme utopique: le mouvement de mai 1968. Paris: Seuil, 1968. 
TRAGTEMBERG, M. Sobre educação, política e sindicalismo. São Paulo: Cortez, 1982.

TRIGUEIRO, D. O problema dos excedentes e a reforma universitária. Revista Brasileira de Estudos Pedagógicos, Rio de Janeiro, v. 48, n. 107, p. 163-168, jul./set. 1967.

VASCONCELOS, I.M. A federalização do ensino superior no Brasil. 2007. Dissertação (Mestrado) - Departamento de Sociologia, Universidade de Brasília, Brasília, DF.

VEIGA, L. Os projetos educativos como projetos de classe: Estado e universidade no Brasil (1954-1964). Educação \& Sociedade, Campinas, v. 4, n. 11, p. 25-71, jan. 1982.

VELLOSO, J. O PIBIC e a formação de cientistas. Brasília, DF: NESUP, 2000.

VIEIRA, S.L.; FARIAS, I.M.S. Politica educacional no Brasil. Brasília, DF: Líber Livro, 2007.

WALLERSTEIN, I. The liberal university under attack. In: WALLERSTEIN, I.; STARr, P. (Ed.). The university crisis reader. New York: Random House, 1971. v. 1. 